\title{
Regulation of transforming growth factor is involved in the efficacy of combined 5 -fluorouracil and interferon alpha- $2 b$ therapy of advanced hepatocellular carcinoma
}

\author{
Youhei Okada ${ }^{1}$, Ting Wang ${ }^{1}$, Kazuhiro Kasai ${ }^{1}$, Kazuyuki Suzuki ${ }^{1}$ and Yasuhiro Takikawa ${ }^{1}$
}

\begin{abstract}
Transforming growth factor-beta (TGF- $\beta$ ) is critical in cancer cell invasion and metastasis. The effects of a treatment that targets TGF- $\beta$ using the combination of interferon alpha (IFNa)-2b and 5-fluorouracil (5-FU) are unknown. Here, we show that the serum levels of TGF- $\beta 1$ prior to the therapy correlate with increased maximum tumor diameter, which is significantly $(p<0.01)$ decreased after the combination therapy. 5-FU increased both the expression and secretion levels of TGF- $\beta 1$ in hepatoma cells, but not in normal hepatocytes. The combination of 5-FU and IFNa-2b synergistically affected cell death. However, a TGF- $\beta 1$ specific inhibitor did not affect the anti-tumor activity of 5-FU. 5FU inhibited the phosphorylation of SMAD2 and reduced the total protein levels of SMAD2, SMAD4, and pINK4b. Conversely, 5-FU stimulated the phosphorylation of extracellular signal-regulated kinase (ERK)1/2. Accordingly, the protein levels of E-cadherin and claudin-1 were reduced in 5-FU-treated cells. The combination of 5-FU and IFNa-2b, and the inhibition of ERK1/2 by a specific inhibitor neutralized the effects of 5-FU on TGF- $\beta$-related signaling molecules and restored their protein levels to those observed in the control. Interestingly, the phosphorylated protein levels of SMAD2 and the total protein levels of E-cadherin and p15INK4b were increased in 5-FU-stimulated HuH-7 cells, but not in Hep G2 cells. Our data suggest that the higher efficacy of the 5-FU and IFNa-2b combination therapy was associated with the regulation of TGF- $\beta$ expression, secretion, and the signals mediated by it.
\end{abstract}

\section{Introduction}

Common hepatocellular carcinoma (HCC) can be treated using diverse approaches that include hepatectomy, transcatheter arterial chemo-embolization (TACE), and radiofrequency ablation (RFA). However, there is no effective therapy for advanced HCC with portal vein tumor thrombosis $(\mathrm{PVTT})^{1}$. A combination therapy of interferon alpha (IFN $\alpha$ )-2b and 5-fluorouracil (5-FU),

\footnotetext{
Correspondence: Ting Wang (tingwang@iwate-med.ac.jp) or Yasuhiro Takikawa (ytakikaw@iwate-med.ac.jp)

'Division of Gastroenterology and Hepatology, Department of Internal

Medicine, Iwate Medical University, Morioka, Iwate, Japan

Edited by N. Barlev
}

which was developed in the early Twenty-first century ${ }^{2,3}$, is being reconsidered as a treatment of advanced HCC. We recently reported the improved survival rate of patients with advanced HCC featuring portal venous invasion using this combination therapy ${ }^{4,5}$. However, the cumulative survival rate was $<50 \%$ at 36 months, which suggested that the treatment is not suitable or produces a poor response for some patients. Better understanding of the mechanistic details of this therapy would help in developing highly effective treatments for advanced HCC and in predicting the causes of adaptation to the therapy.

Several reports have attempted to explain the mechanism of this combination chemotherapy. IFN receptors 

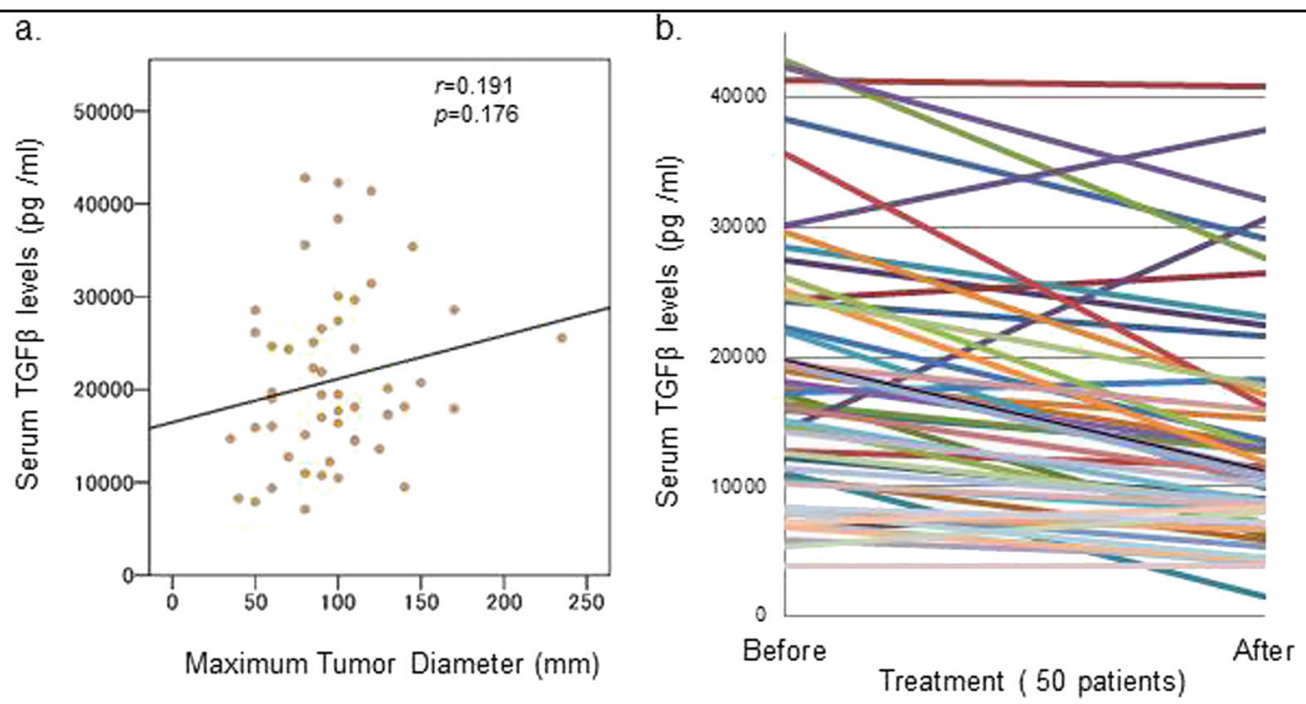

Fig. 1 Detection of TGF- $\beta 1$ serum levels in patients with advanced HCC. a TGF- $\beta 1$ levels before the treatment were used to analyze the correlation with the maximum tumor diameter. A $p$-value and its correlation were calculated in Microsoft Excel 2010. b TGF- $\beta 1$ serum levels in patients before and after treatment were determined according to the manufacturer's instructions. Fifty patients were analyzed. Statistical comparisons were performed using a paired $t$-test. A $p$-value $<0.05$ was considered to be significant

may be involved in inducing the apoptosis of cancer cells that has been observed with this combination chemotherapy ${ }^{6,7}$. Another possibility is the inhibition of the immunosuppression of cancer cells via tumor necrosis factor-related apoptosis-induced ligand (TRAIL) signaling $^{8,9}$. Angiopoietin 2-related anti-angiogenesis might also have a role in the success observed with this treatment $^{10,11}$. However, these studies focused on the individual characteristics that appeared during the progression of advanced HCC, and did not determine the factors affecting the general efficacy of the combination therapy, such as targeting of key molecules or the associated signaling pathways.

As a member of the transforming growth factor-beta superfamily, TGF- $\beta$ activates the SMAD-dependent signaling pathway, which induces apoptosis and inhibits the proliferation of epithelial cells. Therefore, TGF- $\beta$ has long been considered an anti-oncogenic molecule ${ }^{12}$. However, recent research has revealed that mutations in certain components of the TGF- $\beta$ signaling pathway exist in many cancers, especially in TGF- $\beta$ receptor 2 and SMADs ${ }^{13-15}$, which disrupt signal transduction and the subsequent inhibition of proliferation and apoptosis. In these mutants, TGF- $\beta$ activates members of the mitogen-activated protein kinase (MAPK) pathway, such as extracellular signalregulated kinase 1 and 2 (Erk1/2, or p44/42), c-Jun Nterminal kinases (JNKs), and p38 isoforms (p38 MAPK). This TGF- $\beta$-induced SMAD-independent mitogenic signaling protects cancer cells from apoptotic cell death and induces epithelial-mesenchymal transition (EMT), which renders the tumor cells metastatic ${ }^{13}, 16,17$. In addition,
TGF- $\beta$ is secreted excessively by several cancerous tissues, and contributes to the maintenance of the cancer stem cell population, immunosuppression, and angiogenesis ${ }^{18,}{ }^{19}$.

Considering the importance of TGF- $\beta$ in cancer development, we evaluated the relationship between the serum levels of TGF- $\beta$ and the efficacy of the IFN $\alpha-2 b / 5-F U$ combination therapy. We also studied the effects of 5-FU with or without IFN $\alpha-2 b$ on the regulation of TGF $\beta$.

\section{Results}

\section{Serum levels of TGF- $\beta 1$ in patients with advanced HCC}

On the basis of our previous results that the mean survival rate of patients is improved after the IFN $\alpha-2 b / 5-$ FU combination therapy ${ }^{4,5}$, we first quantified the serum levels of TGF- $\beta 1$ in patients with advanced HCC before and after the combination therapy to determine whether the efficacy of the therapy correlated with the regulation of TGF- $\beta$ levels. Serum levels of TGF- $\beta 1$ before the therapy showed a tendency towards correlation with increased maximum tumor diameter, which is used to evaluate the progress of HCC (Fig. 1a). Therapy was associated with significantly decreased serum levels of TGF- $\beta 1 \quad(p<0.01$; Fig. $1 \mathrm{~b})$. Seventeen patients had a background of hepatitis $\mathrm{C}$ virus (HCV) infection. Ten of the 17 patients improved and seven worsened, as determined by a computed tomography (CT) scan 1 month after receiving the combination therapy. In these 17 patients, the serum levels of TGF- $\beta 1$ decreased following the therapy, with no significant difference in the therapyrelated change in TGF- $\beta 1$ levels between the patients who improved and worsened (Supplemental Data). 

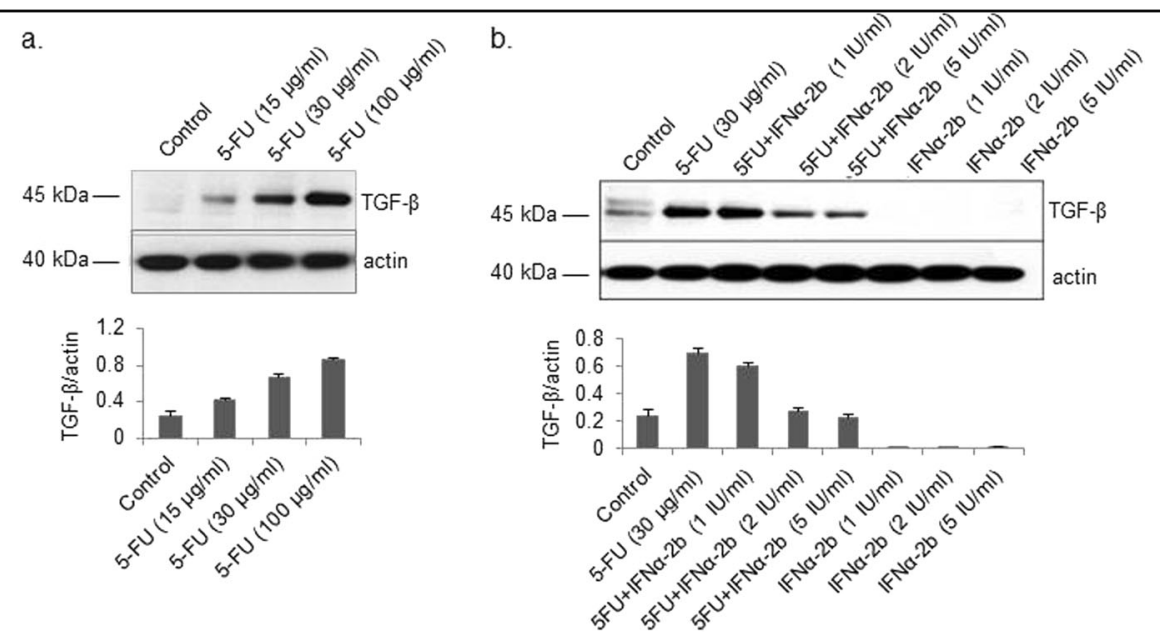

Fig. 2 Effects of 5-FU and IFNa-2b alone and in combination on TGF- $\boldsymbol{\beta}$ levels in Hep G2 cells. Cells were treated with 0, 15, 30, and 100 $\mu \mathrm{g} / \mathrm{mL}$ 5 -FU for $24 \mathrm{~h}$ (a) or with $30 \mathrm{\mu g} / \mathrm{mL}$ 5-FU, IFNa-2b $(1,2,5 \mathrm{IU} / \mathrm{mL})$, or 5-FU and IFNa-2b for $24 \mathrm{~h}$ (b). TGF $\beta$ levels in the cell lysates were determined by western blotting. Results are expressed as the means $\pm \mathrm{SD}(n=3)$

\section{Effects of 5-FU or IFNa-2b alone and in combination on TGF- $\beta$ expression in Hep $\mathrm{G} 2$ cells}

The foregoing data prompted an in vitro assessment of whether the efficacy of the combination therapy results from a synergistic effect of 5-FU and IFN $\alpha-2 b$ on the regulation of TGF- $\beta$. Unexpectedly, we found that 5 -FU treatment stimulated and increased the protein levels of TGF- $\beta$ in the lysates of cultured Hep G2 cells in a dose-dependent manner (Fig. 2a). In contrast, no TGF- $\beta$ was detected in cells treated with IFN $\alpha-2 b$ (Fig. 2b). The combination of 5-FU and $1-5 \mathrm{IU} / \mathrm{mL}$ IFN $\alpha-2 \mathrm{~b}$ completely inhibited the expression of TGF- $\beta$ induced by 5 -FU (Fig. $2 b$ ).

\section{Effects of 5-FU treatment alone, or in combination with IFNa-2b or TGF- $\beta$ receptor inhibitor, on the viability and apoptosis of Hep G2 cells}

Since 5-FU is a potent anti-tumor reagent, we quantified cell viability to determine whether the increased levels of TGF- $\beta$ stimulated by the 5 -FU treatment contributed to the anti-tumor activity of 5-FU. Treatment with 5-FU significantly decreased the number of viable cells (Fig. 3a) and induced cell apoptosis (Fig. 3b, c), and the combination of 5-FU and IFN $\alpha-2 b$ generated a synergistic effect, consistent with previous reports (Fig. 3a-c) ${ }^{20-22}$. However, treatment of the cells with SB-431542, a potent and specific inhibitor of the TGF- $\beta 1$ receptor, prior to 5 -FU treatment did not significantly change the effects of 5-FU treatment alone ( $p>0.05$; Fig. 3a-c).

\section{Effects of 5-FU on TGF- $\beta$-related signaling molecules}

The effect of 5 -FU on TGF- $\beta$-induced apoptosis signals was investigated. 5-FU inhibited the phosphorylation of SMAD2 and reduced the total protein levels of pINK4b (Fig. 4a). Conversely, 5-FU stimulated the phosphorylation of ERK1/2, a TGF- $\beta$-induced EMT molecule. During the progression of EMT, tight junction proteins, like claudins and adherens junction proteins like E-Cadherin are usually downregulated ${ }^{23}$, 24. Consistent with these observations, we observed that the protein levels of E-cadherin and claudin-1 were reduced in the cells treated with 5-FU (Fig. 4b). On the other hand, IFN $\alpha$-2b stimulated the phosphorylation of SMAD2, but not ERK1/2, increased the total protein levels of pINK4b, and did not affect the levels of E-cadherin and claudin-1. The combination of 5 -FU and IFN $\alpha-2 b$ inhibited the effects of 5 -FU on the aforementioned TGF- $\beta$-related signaling molecules (Fig. 4a, b). In addition, similar to the effects of IFN $\alpha-2 b$, U0126 (a MEK-specific inhibitor and an upstream effector of ERK1/2) inhibited the negative effect of 5-FU on the regulation of E-cadherin and claudin-1 (Fig. 4c). The other EMT molecules, vimentin and slug showed no expression. In addition, there was no obvious change in the expression of snail, TCF8/ZEB1, ZO-1 and $\beta$-catenin upon treatment with 5 -FU in comparison to controls (data not shown).

\section{5-FU increases expression and secretion levels of TGF- $\beta 1$ in Hep G2 and HuH-7 cells}

We also compared the effects of 5-FU on the expression and secretion of TGF- $\beta$ in Hep G2 and HuH-7 hepatocarcinoma cells, and normal alpha mouse liver AML -12 hepatocytes. Time- and dose-course experiments revealed increased TGF- $\beta$ levels in 5-FU treated Hep G2 and HuH7 cells. In HuH-7 cells, the levels of TGF- $\beta$ levels peaked upon treatment with $30 \mu \mathrm{g} / \mathrm{mL}$ 5-FU (Fig. 5a), whereas there was a progressive increase in TGF- $\beta$ levels in Hep G2 cells. Conversely, a TGF- $\beta$ peak appeared in Hep G2 cells that were treated for $24 \mathrm{~h}$ with 5 -FU, whereas there 


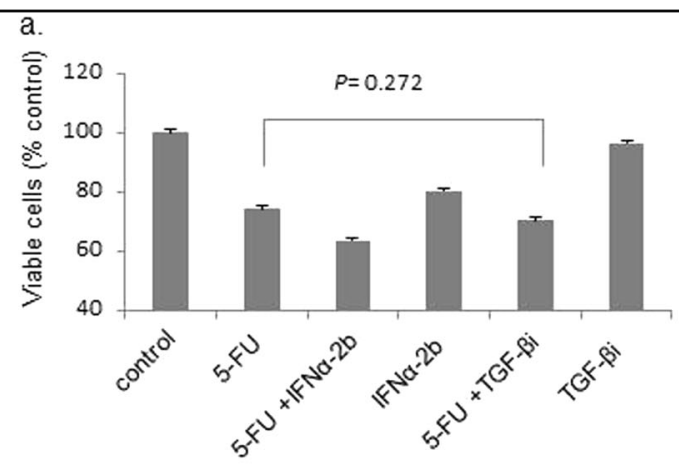

b.
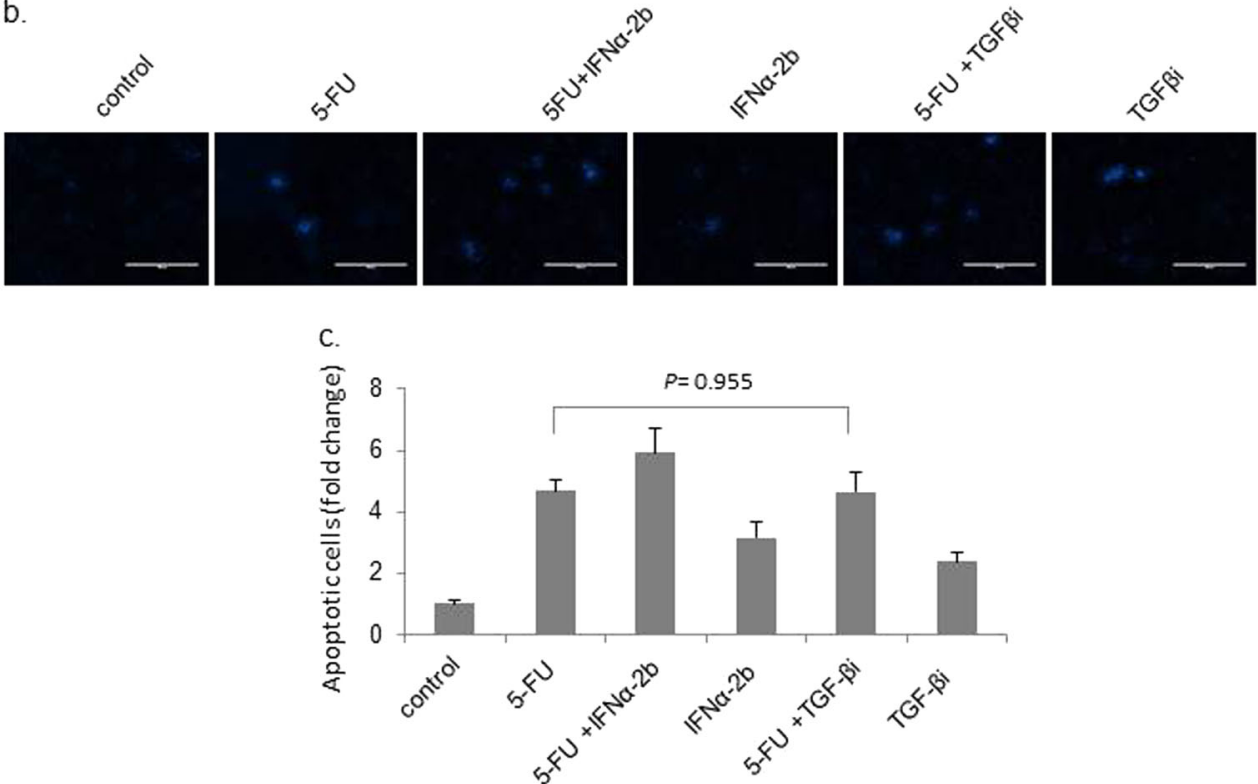

Fig. 3 Effects of 5-FU treatment alone, or in combination with IFNa-2b or TGF- $\beta$ receptor inhibitor, on the viability and apoptosis of Hep G2 cells. a Cells were treated with $15 \mu \mathrm{g} / \mathrm{mL} 5-\mathrm{FU}, 2 \mathrm{IU} / \mathrm{mL}$ IFNa-2b, or a combination of both for $48 \mathrm{~h}$. In additional experiments, cells were pretreated with $10 \mu \mathrm{M}$ SB-431542 (a TGF- $\beta$ inhibitor) before treatment with 5-FU. The number of viable cells was evaluated by checking the optical density at $450 \mathrm{~nm}$. b Cells were given the same treatment as described in $\mathbf{a}$; thereafter, the apoptotic cells were stained, photographed (scale $=400$ $\mu \mathrm{M})$, and counted (c) as described in the materials and methods section. The statistical analysis was carried out using one-way ANOVA-POST HOC (Tukey's HSD) analysis. A $p$-value $<0.05$ was considered to be significant. Results are expressed as the means \pm SD $(n=3)$

was a progressive increase in TGF- $\beta$ levels for up to $48 \mathrm{~h}$ in $\mathrm{HuH}-7$ cells (Fig. 5b). We further compared the TGF- $\beta$ secretion pattern of these hepatoma cell lines. The baseline level of TGF- $\beta$ in the supernatant fraction of cultured HuH-7 cells was higher than that of Hep G2 cells. The peak in TGF- $\beta$ secretion occurred upon a 48-h treatment of either cell line with $15 \mu \mathrm{g} / \mathrm{mL} 5$-FU (Fig. 5c, d). In contrast, there was no expression (Fig. $5 \mathrm{a}, \mathrm{b}$ ) or secretion (Fig. 6b) of TGF- $\beta$ in normal AML-12 hepatocytes with or without 5 -FU treatment.

Differences in the effects of 5-FU and IFNa-2b combination treatment on TGF- $\beta$ regulation between Hep G2 and $\mathrm{HuH}-$ 7 cells

The combination of 5-FU and IFN $\alpha-2 b$ decreased both the expression and secretion of TGF- $\beta$ in Hep G2 cells compared to cells treated with 5-FU alone. However, in $\mathrm{HuH}-7$ cells, the combination therapy decreased only the secretion of TGF- $\beta$, with no effect on the protein levels (Fig. 6a, b). Interestingly, the phosphorylated protein levels of SMAD2 and the total protein levels of E-cadherin and p15INK4b were increased in 5-FU-stimulated $\mathrm{HuH}-7$ cells, in contrast to the inhibition of these TGF- $\beta$-induced signaling molecules in 5-FU-stimulated Hep G2 cells (Fig. 6c).

\section{Discussion}

Elevation in the serum levels of TGF- $\beta$ or TGF- $\beta$ expression have been reported in various cancers, and particularly during the progression of advanced $\mathrm{HCC}^{25-}$ 30. TGF- $\beta 1$ is a useful biomarker of prostate cancer and small $\mathrm{HCC}^{28,}{ }^{29}$. Presently, although no significant 

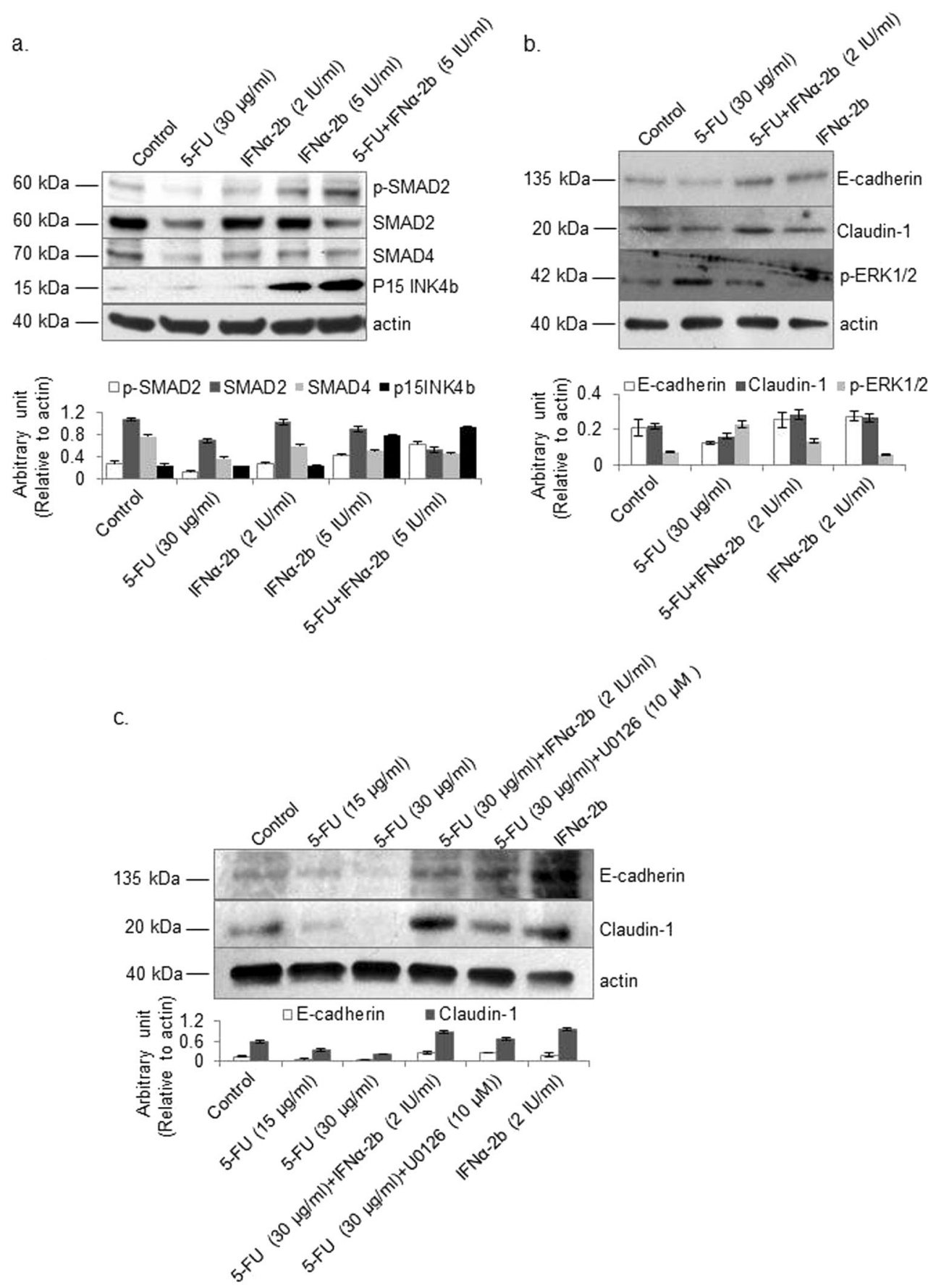

Fig. 4 Effects of 5-FU and IFNa-2b alone and in combination on TGF- $\boldsymbol{\beta}$-mediated signaling. Hep G2 cells were treated with 5-FU and/or IFNa$2 \mathrm{~b}$ at the indicated concentrations for $24 \mathrm{~h}$. a The protein levels of p-SMAD2, SMAD2, SMAD4, and p15INK4b were detected by western blotting. $\mathbf{b}$ In another experiment, levels of EMT molecules including E-cadherin, claudin-1, and p-ERK1/2 were detected by western blotting as described in the materials and methods section. c Besides the treatment of 5-FU and IFNa-2b alone and in combination, the ERK1/2 inhibitor U0126 was used to clarify the role of ERK $1 / 2$ in the regulation of E-cadherin and claudin-1 by 5-FU. Actin was detected as an internal control. The quantitative data are presented as the means \pm SD $(n=3)$

difference was found, possibly because all the subjects were stage IV, serum TGF- $\beta$ levels tended to correlate positively with maximum tumor diameter. More importantly, TGF- $\beta$ levels decreased in patients who were administered a combined chemotherapy of 5 -FU and IFN $\alpha-2 b$, accompanied by a high efficacy of the therapy 
a.
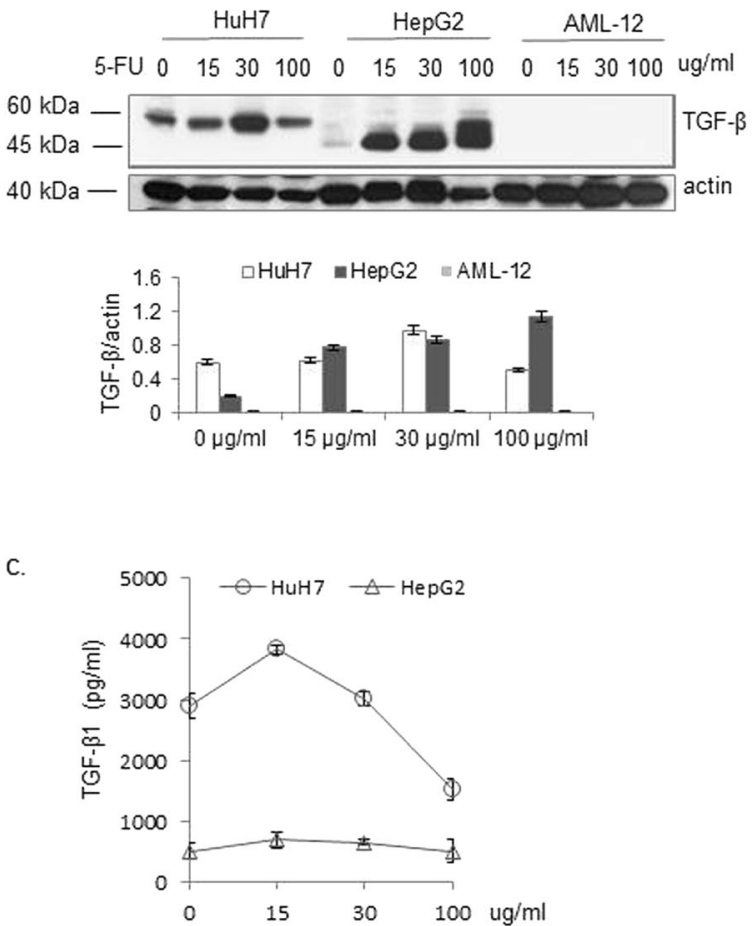

b.

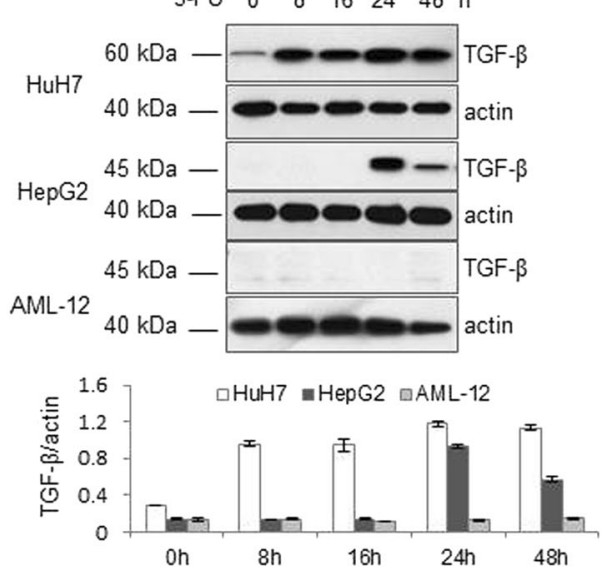

d.

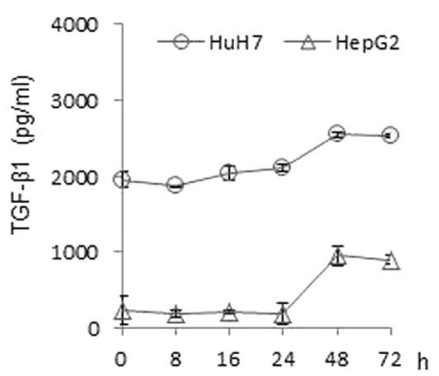

Fig. 5 Cell-dependent regulation of TGF- $\beta$ expression and secretion by $\mathbf{5 - F U}$. HuH-7, Hep G2, and AML-12 cells were treated with different concentrations of 5-FU as indicated (a), and $30 \mu \mathrm{g} / \mathrm{mL} 5$-FU for the indicated time periods (b). TGF- $\beta$ was detected by western blotting. TGF- $\beta$ secretion was measured in HuH-7 and Hep G2 cells as described in Materials and Methods (c, d). Results are expressed as the means \pm SD ( $n=3$ )

with a mean survival rate of 29.9 months ${ }^{4}$. The data suggest that the reduction in TGF- $\beta$ levels may be useful to predict the efficacy of the combination therapy.

Surprisingly, 5-FU increased both the protein and secretion levels of TGF- $\beta$, and regulated the TGF- $\beta$ induced signaling in Hep G2 and HuH-7 hepatoma cells, but not in normal hepatocytes. A recent study reported that 5 -FU can activate the TGF- $\beta$ pathway and reasonably upregulate the expression of TGF- $\beta$ in an autocrine manner in drug-resistant colorectal carcinoma cells ${ }^{31}$. The association between 5 -FU and TGF- $\beta$ signaling has also been described in human HCC cells ${ }^{32}$. It is possible that 5 -FU regulates TGF- $\beta$ signaling indirectly via poly (ADP-ribose) polymerase-1 (PARP-1), a nuclear enzyme that is conventionally linked to DNA repair ${ }^{33,34}$. How 5FU regulates TGF- $\beta$ and its pathway in HCC cells, and whether its function is limited only to cancer cells is unclear and requires further investigations.

TGF- $\beta$ regulates both apoptosis and EMT of hepatocytes. However, resistance of hepatoma cells to TGF- $\beta$ induced apoptosis has been reported ${ }^{35}$. In the present study, a specific TGF- $\beta$ receptor inhibitor did not antagonize the effects of 5-FU on Hep G2 cell viability and apoptosis. Additionally, although the combination of 5-
FU and IFN $\alpha-2 b$ was more lethal to cancer cells than 5FU alone, TGF- $\beta$ expression and secretion decreased in cells treated with the drug combination compared to cells treated with 5-FU alone. Our data indicate that the increase in TGF- $\beta$ levels does not contribute to the anticancer activity of 5-FU in Hep G2 cells. Furthermore, we found that 5 -FU inhibited TGF- $\beta$-mediated apoptosis signaling but stimulated the activation of ERK1/2 and inhibited the protein levels of E-cadherin and claudin-1. In addition, inhibition of ERK1/2 neutralized the effects of 5 -FU on the protein levels of E-cadherin and claudin-1. These events are indications of prompt TGF- $\beta$-mediated EMT signaling via ERK1/2. EMT is marked by decreased E-cadherin expression which is, in turn, regulated by transcriptional regulators such as slug, snail1, and ZEB1. ${ }^{36}$ However, our present study indicates that these molecules are not involved in 5-FU-stimulated TGF- $\beta$ signaling because their levels remained unaffected upon stimulation by 5 -FU. Further research is needed to confirm these results and to clarify the roles of other EMT transcriptional regulators like TWIST1, TCF4, and TCF $3^{36}$ in the context of how 5-FU stimulation affects EMT signaling. In addition to the data on signaling, we also observed that the morphology of Hep G2 colonies underwent an EMT- 

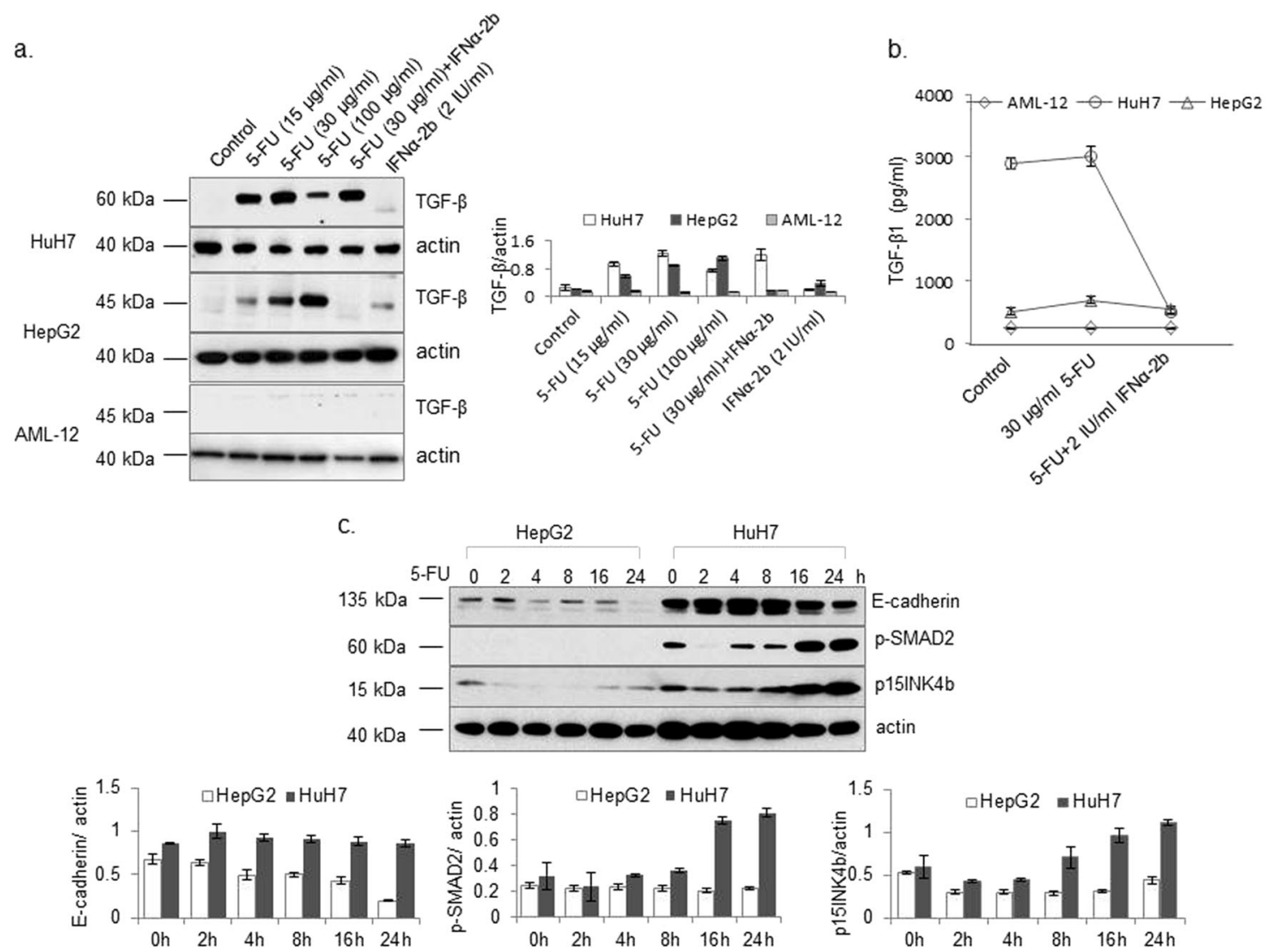

Fig. 6 Responses of different cells to 5-FU, IFNa-2b, and combined treatment with respect to TGF- $\beta$ levels and TGF- $\beta$-mediated signaling. Hep G2, HuH-7, and AML-12 cells were individually treated with 5-FU, IFNa-2b, and a combination of 5-FU and IFNa-2b for $24 \mathrm{~h}$. TGF- $\beta$ levels in cell lysates (a) and culture supernatants (b) were detected. (c) Both Hep G2 and HuH-7 cells were treated with 5-FU for different periods as indicated. The levels of E-cadherin, p-SMAD2, and p15INK4b were detected by western blot. Actin was detected as an internal control. Results are expressed as the means \pm SD $(n=3)$

like change, and their invasion and migration accelerated, upon a 24-h treatment with the culture supernatant of 5FU-treated cells. We detected secretion of TGF- $\beta$ in the latter cells (data not shown). Further investigations are ongoing on factors that reduce the cytotoxic effects of the reagents and to obtain a more direct proof of 5-FUinduced EMT. These investigations include screening of cells to detect resistance to the cytotoxic activity of antitumor reagents, determination of the best dose and period of treatment with 5-FU, and whether to administer 5-FU in combination with IFN $\alpha-2 b$.

As we presently confirmed, IFN $\alpha$ inhibits the expression of TGF- $\beta^{37}$. We provide the first evidence that IFN $\alpha-2 b$ can antagonize the effects of 5 -FU on TGF- $\beta$ expression and TGF- $\beta$-mediated signaling. Therefore, it can be assumed that the higher efficacy of the combination therapy for advanced HCC happened by targeting both TGF- $\beta$ and its downstream signals. Indeed, medical insurance does not cover the use of IFN $\alpha-2 b$ in treatment of advanced HCC. Cisplatin ${ }^{38}$, sorafenib ${ }^{39}$ and more recently, the TGF- $\beta$ receptor I kinase inhibitor, LY2157299 monohydrate ${ }^{40}$, have good efficacy against advanced HCC. The present data indicate that, except for IFN $\alpha-2 \mathrm{~b}$, co-treatment involving 5-FU and other compounds or inhibitors of TGF- $\beta$ and its signaling will be efficacious. This is consistent with a prior study that described the therapeutic value of the combination of a TGF- $\beta$ receptor kinase inhibitor with the 5 -FU analog, S1, for the treatment of scirrhous gastric carcinoma with lymph node metastasis ${ }^{41}$.

Presently, TGF- $\beta$ expression and secretion were unaffected by 5 -FU treatment of normal hepatocytes, compared to Hep G2 and HuH-7 hepatoma cells. Moreover, the two hepatoma cell lines responded differently to treatment with 5-FU alone or in combination with IFN $\alpha$ $2 \mathrm{~b}$. The collective data indicate a cell-dependent function of 5-FU. Interestingly, the Hep G2 cell line was established from a HBV-positive male with a primary hepatoma $^{42,43}$, while $\mathrm{HuH}-7$ cells possess $\mathrm{HCV}$ replicons capable of auto-replication ${ }^{44}$. Thus, our in vitro data 
might explain the variation in the clinical efficacy of the combination therapy. In other words, the efficacy of the therapy may differ between patients with $\mathrm{HCV}$ or $\mathrm{HBV}$ background. It has been reported that patients with HCC and a HCV-positive background had higher survival rates and longer survival periods than patients who were HCVnegative or produced higher levels of TGF- $\beta$ receptor $2^{45}$. Furthermore, in contrast to Hep G2 cells, 5-FU increased the levels of p-SAMD2 and p15INK4b, and maintained or even increased the level of E-cadherin in $\mathrm{HuH}-7$ cells. These observations indicate that apoptosis signaling increased in 5-FU-treated $\mathrm{HuH}-7$ cells in contrast with Hep G2 cells. In cases with an HCV background that were analyzed, although the serum levels of TGF- $\beta$ decreased after the combination therapy in all the patients, $41.2 \%$ of the cases responded poorly to the therapy with a continued worsening of their condition, and there were no significant differences in TGF- $\beta$ levels between patients who worsened and improved. These data suggest that excessive inhibition of TGF- $\beta$ and its signal may weaken the apoptotic function of 5-FU in patients with an $\mathrm{HCV}$ background, which could lead to poor or no response to the combination therapy.

In Japan and China, the majority of HCC patients have an HCV and HBV background, respectively. Proper treatment of these patients will undoubtedly determine the efficacy of HCC treatment, especially for those in advanced stages. The present data clarify the various effects of 5-FU and IFN $\alpha-2 b$ applied alone and in combination, on the regulation of TGF- $\beta$ levels and its signals in two hepatoma cells. The knowledge gained will aid in determining the mechanism of the combination chemotherapy, which will in turn drive the formulation of better therapies for advanced HCC.

\section{Materials and methods}

\section{Subjects}

Fifty patients with advanced HCC (stage IV-A/B) were treated using a subcutaneous administration of polyethylene glycol (PEG)-IFN $\alpha-2 b(50-100 \mu \mathrm{g}$ on day 1 of each week for 4 weeks) and intra-arterial infusion of 5-FU $(250 \mathrm{mg} /$ day for $5 \mathrm{~h}$ on days $1-5$ of each week for 4 weeks). Blood was withdrawn before and after the therapy and centrifuged at $1500 \times g$ for $10 \mathrm{~min}$. The resulting serum was stored in aliquots at $-80{ }^{\circ} \mathrm{C}$. The largest tumor diameter was also determined in the patients. Approval for the study was obtained from the institutional review board (H19-87) of Iwate Medical University, Morioka, Japan, and informed consent was obtained from the patients' relatives.

\section{Cells}

Human HuH-7 and Hep G2 hepatocarcinoma cells were purchased from the American Type Culture
Collection (ATCC, Manassas, VA, USA). The cells were cultured in Dulbecco's modified Eagle's medium (DMEM; Thermo Fisher Scientific, Rockford, IL, USA) containing $10 \%$ fetal bovine serum, (FBS; Thermo Fisher Scientific) and $100 \mathrm{U} / \mathrm{mL}$ penicillin-streptomycin (Sigma-Aldrich, St. Louis, MO, USA). Mouse AML-12 hepatocytes were kindly supplied by Professor Itaru Kojima, Gunma University, Japan. The cells were cultured in DMEM and Ham's F-12 nutrient mixture. (1:1, Thermo Fisher Scientific) containing 10\% FBS until $80 \%$ confluency was reached. After starvation, the cells were treated with 5-FU (Kyowa Kirin, Tokyo, Japan), IFN $\alpha-2 b$ (Funakoshi Co., Ltd., Tokyo, Japan), or the combination of 5-FU and IFN $\alpha-2 b$ in the absence or presence of an inhibitor of TGF- $\beta$. Some experiments also included SB-431542, which is the specific inhibitor of receptor kinase (SigmaAldrich), and U0126, which inhibits ERK kinases (MEK; Promega Corporation, WI, USA).

\section{Analysis of the levels of TGF- $\beta 1$}

TGF $\beta$ - 1 levels were assessed in patients, before and after administering therapy, and in the cell culture supernatant of hepatoma cells using the Quantikine Human TGF- $\beta 1$ Immunoassay Kit (R\&D Systems Inc., Minneapolis, MN, USA). TGF $\beta-1$ levels in the cell culture supernatant of AML-12 cells were assessed using the Quantikine Mouse/ Rat/Porcine/Canine TGF- $\beta 1$ Immunoassay Kit (R\&D Systems, Inc., Minneapolis, MN, USA).

\section{Western blot analysis}

Total protein was isolated from hepatocytes using a total protein extraction kit from the BioChain Institute (Newark, CA, USA) according to the manufacturer's instructions. Ten micrograms of protein from each sample was separated using $10 \%$ sodium dodecyl sulfate polyacrylamide gel electrophoresis (SDS-PAGE) and electro-transferred to a polyvinylidene difluoride membrane. Immunoblotting was performed using antibodies from the Epithelial-mesenchymal Transition (EMT) Antibody Sampler Kit and specific antibodies against TGF- $\beta$, phospho (p)-SMAD2, SMAD2, SMAD4, p15INK4b, p-ERK1/2 (Cell Signaling Technology Japan, K.K., Tokyo, Japan). The antibody against $\beta$-actin was purchased from Santa Cruz Biotechnology, Santa Cruz, CA, USA. All antibodies showed reactivity to mouse and human cells. The immuno-reactive bands were visualized with an enhanced chemiluminescence reagent (GE Healthcare, Little Chalfont, Buckinghamshire, UK) and quantified with Image J software.

\section{Cell viability assay}

Hep G2 cells were treated for $48 \mathrm{~h}$ under predetermined conditions. The number of viable cells was evaluated by adding SF cell counting reagent (Nacalai Tesque, Tokyo, 
Japan) directly to the cells. Absorbance was measured at $450 \mathrm{~nm}\left(\mathrm{~A}_{450}\right)$ using an Immuno-Mini NJ-2300 microplate reader (Inter Med, Tokyo, Japan).

\section{Evaluation of apoptosis of Hep G2 cells}

Hep G2 cells were treated for $48 \mathrm{~h}$ under predetermined conditions. Apoptotic cells were stained with 4',6-diamidino-2-phenylindole dihydrochloride (DAPI; Dojindo, Japan). The cells were scored under an inverted fluorescence microscope (ECLIPSE TE300, Nikon, Japan) at $20 \times$ magnification, and were photographed using a digital camera (DXC-S500/OL, Olympus, Tokyo, Japan). Apoptotic cells and non-apoptotic cells present in three randomly chosen microscopic fields were counted, and the percentage of apoptotic cells was calculated.

\section{Statistical analysis}

Statistical analysis was carried out using $t$-test (Fig. 1b; Supplemental Data) and one-way ANOVA-POST HOC (Tukey's HSD) analysis (Fig. 3a, c, SPSS statistics 17.0 software package, SPSS Japan Inc.). A $p$-value $<0.05$ was considered significant. Data are presented as the mean \pm standard deviation (SD).

\section{Acknowledgements}

This study was supported by a Grants-in-Aid for Scientific Research (JP 15K09020) from the Japan Society for the Promotion of Science. We thank Ms. Asako Watanabe for technical assistance.

\section{Conflict of interest}

The authors declare that they have no conflict of interest.

\section{Publisher's note}

Springer Nature remains neutral with regard to jurisdictional claims in published maps and institutional affiliations.

Supplementary Information accompanies this paper at (https://doi.org/ 10.1038/s41420-018-0040-y).

Received: 25 November 2017 Revised: 22 January 2018 Accepted: 6 February 2018

Published online: 12 March 2018

\section{References}

1. Schwartz, M., Roayaie, S. \& Konstadoulakis, M. Strategies for the management of hepatocellular carcinoma. Nat. Clin. Pract. Oncol. 4, 424-432 (2007).

2. Sakon, M. et al. Combined intraarterial 5-fluorouracil and subcutaneous interferon-alpha therapy for advanced hepatocellular carcinoma with tumor thrombi in the major portal branches. Cancer 94, 435-442 (2002).

3. Obi, S. et al. Combination therapy of intraarterial 5-fluorouracil and systemic interferon-alpha for advanced hepatocellular carcinoma with portal venous invasion. Cancer 106, 1990-1997 (2006).

4. Kasai, K. et al. Therapeutic efficacy of combination therapy with intra-arterial 5fluorouracil and systemic pegylated interferon alpha-2b for advanced hepatocellular carcinoma with portal venous invasion. Cancer 118, 3302-3310 (2012).

5. Kasai, K. et al. Combination therapy of intra-arterial 5-fluorouracil and systemic pegylated interferon alpha-2b for advanced hepatocellular carcinoma. Int. J. Clin. Oncol. 16, 221-229 (2011).
6. Ota, H. et al. Treatment of hepatocellular carcinoma with major portal vein thrombosis by combined therapy with subcutaneous interferon-alpha and intra-arterial 5-fluorouracil; role of type 1 interferon receptor expression. Br. J. Cancer 93, 557-564 (2005).

7. Nagano, H. et al. Interferon-alpha and 5-fluorouracil combination therapy after palliative hepatic resection in patients with advanced hepatocellular carcinoma, portal venous tumor thrombus in the major trunk, and multiple nodules. Cancer 110, 2493-2501 (2007).

8. Nakamura, M. et al. Role of the Fas/FasL pathway in combination therapy with interferon-alpha and fluorouracil against hepatocellular carcinoma in vitro. J. Hepatol. 46, 77-88 (2007).

9. Yamamoto, T. et al. Partial contribution of tumor necrosis factor-related apoptosis-inducing ligand (TRAIL)/TRAlL receptor pathway to antitumor effects of interferon-alpha/5-fluorouracil against Hepatocellular Carcinoma. Clin. Cancer Res. 10, 7884-7895 (2004).

10. Wada, $\mathrm{H}$. et al. Combination therapy of interferon-alpha and 5-fluorouracil inhibits tumor angiogenesis in human hepatocellular carcinoma cells by regulating vascular endothelial growth factor and angiopoietins. Oncol. Rep. 18, 801-809 (2007).

11. Wada, H. et al. Combination of interferon-alpha and 5-fluorouracil inhibits endothelial cell growth directly and by regulation of angiogenic factors released by tumor cells. BMC Cancer 9, 361 (2009).

12. Massague, J. TGFbeta signalling in context. Nat. Rev. Mol. Cell. Biol. 13, 616-630 (2012).

13. Padua, D. \& Massague, J. Roles of TGFbeta in metastasis. Cell Res. 19, 89-102 (2009).

14. Nagaraj, N. S. \& Datta, P. K. Targeting the transforming growth factor-beta signaling pathway in human cancer. Expert Opin. Investig. Drugs 19, 77-91 (2010).

15. Tesseur, I., Zou, K., Berber, E., Zhang, H. \& Wyss-Coray, T. Highly sensitive and specific bioassay for measuring bioactive TGF-beta. BMC Cell Biol. 7, 15 (2006)

16. Akhurst, R. J. \& Hata, A. Targeting the TGFbeta signalling pathway in disease. Nat. Rev. Drug Discov. 11, 790-811 (2012).

17. Miyazono, K. Transforming growth factor-beta signaling in epithelialmesenchymal transition and progression of cancer. Proc. Jpn. Acad. Ser. B Phys. Biol. Sci. 85, 314-323 (2009).

18. Pickup, M., Novitskiy, S. \& Moses, H. L. The roles of TGFbeta in the tumour microenvironment. Nat. Rev. Cancer 13, 788-799 (2013).

19. Thomas, D. A. \& Massague, J. TGF-beta directly targets cytotoxic T cell functions during tumor evasion of immune surveillance. Cancer Cell 8, 369-380 (2005).

20. Longley, D. B., Harkin, D. P. \& Johnston, P. G. 5-fluorouracil: mechanisms of action and clinical strategies. Nat. Rev. Cancer 3, 330-338 (2003).

21. Sui, X. et al. Autophagy and chemotherapy resistance: a promising therapeutic target for cancer treatment. Cell Death Dis. 4, e838 (2013).

22. $\mathrm{Hu}$, Z. et al. Enhancement of anti-tumor effects of 5-fluorouracil on hepatocellular carcinoma by low-intensity ultrasound. J. Exp. Clin. Cancer Res. 35, 71 (2016).

23. Shiozaki, A. et al. Claudin 1 mediates TNFalpha-induced gene expression and cell migration in human lung carcinoma cells. PLOS ONE 7, e38049 (2012).

24. Lamouille, S., Xu, J. \& Derynck, R. Molecular mechanisms of epithelialmesenchymal transition. Nat. Rev. Mol. Cell Biol. 15, 178-196 (2014).

25. Pang, M. F. et al. TGF-beta1-induced EMT promotes targeted migration of breast cancer cells through the lymphatic system by the activation of CCR7/ CCL21-mediated chemotaxis. Oncogene 35, 748-760 (2016).

26. Barcellos-Hoff, M. H. \& Akhurst, R. J. Transforming growth factor-beta in breast cancer: too much, too late. Breast Cancer Res. 11, 202 (2009).

27. Xu, J., Menezes, J., Prasad, U. \& Ahmad, A. Elevated serum levels of transforming growth factor beta1 in Epstein-Barr virus-associated nasopharyngeal carcinoma patients. Int. J. Cancer 84, 396-399 (1999).

28. Reis, S. T. et al. Tgf-beta1 expression as a biomarker of poor prognosis in prostate cancer. Clin. (Sao Paulo) 66, 1143-1147 (2011).

29. Song, B. C. et al. Transforming growth factor-beta1 as a useful serologic marker of small hepatocellular carcinoma. Cancer 94, 175-180 (2002).

30. Lin, T. H. et al. High serum transforming growth factor-beta1 levels predict outcome in hepatocellular carcinoma patients treated with sorafenib. Clin. Cancer Res. 21, 3678-3684 (2015).

31. Romano, G. et al. The TGF-beta pathway is activated by 5 -fluorouracil treatment in drug resistant colorectal carcinoma cells. Oncotarget 7, 22077-22091 (2016). 
32. Nomura, Y. et al. De novo emergence of mesenchymal stem-like CD105 +cancer cells by cytotoxic agents in human hepatocellular carcinoma. Transl. Oncol. 10, 184-189 (2017).

33. Akpinar, B. et al. 5-Fluorouracil-induced RNA stress engages a TRAIL-DISC dependent apoptosis axis facilitated by p53. Oncotarget 6, 43679-43697 (2015).

34. Zhang, P. et al. PARP-1 regulates expression of TGF-beta receptors in T cells. Blood 122, 2224-2232 (2013).

35. Buenemann, C. L., Willy, C., Buchmann, A., Schmiechen, A. \& Schwarz, M Transforming growth factor-beta1-induced Smad signaling, cell-cycle arrest and apoptosis in hepatoma cells. Carcinogenesis 22, 447-452 (2001).

36. Imani, S., Hosseinifard, H., Cheng, J., Wei, C. \& Fu, J. Prognostic value of EMTinducing transcription factors (EMT-TFs) in metastatic breast cancer: a systematic review and meta-analysis. Sci. Rep. 6, 28587 (2016).

37. Yu, Y., Huang, R., Zong, X., He, X. \& Mo, W. INFalpha-2b inhibitory effects on $\mathrm{CD} 4(+) \mathrm{CD} 25(+) \mathrm{FOXP3}(+)$ regulatory $T$ cells in the tumor microenvironment of C57BL/6 J mice with melanoma xenografts. BMC Cancer 16, 397 (2016).

38. Park, S. H. et al. Systemic chemotherapy with doxorubicin, cisplatin and capecitabine for metastatic hepatocellular carcinoma. BMC Cancer 6, 3 (2006).
39. Keating, G. M. \& Santoro, A. Sorafenib: a review of its use in advanced hepatocellular carcinoma. Drugs 69, 223-240 (2009).

40. de Gramont, A., Faivre, S. \& Raymond, E. Novel TGF-beta inhibitors ready for prime time in onco-immunology. Oncoimmunology 6, e1257453 (2017).

41. Shinto, O. et al. Combination effect of a TGF-beta receptor kinase inhibitor with 5-FU analog S1 on lymph node metastasis of scirrhous gastric cancer in mice. Cancer Sci. 101, 1846-1852 (2010).

42. Aden, D. P., Fogel, A., Plotkin, S., Damjanov, I. \& Knowles, B. B. Controlled synthesis of HBsAg in a differentiated human liver carcinoma-derived cell line. Nature 282, 615-616 (1979).

43. Huber, B. E., Dearfield, K. L., Williams, J. R., Heilman, C. A. \& Thorgeirsson, S. S. Tumorigenicity and transcriptional modulation of c-myc and N-ras oncogenes in a human hepatoma cell line. Cancer Res. 45, 4322-4329 (1985).

44. Kapadia, S. B. \& Chisari, F. V. Hepatitis C virus RNA replication is regulated by host geranylgeranylation and fatty acids. Proc. Natl Acad. Sci. USA 102 2561-2566 (2005)

45. Sakabe, T. et al. Identification of the genes chemosensitizing hepatocellular carcinoma cells to interferon-alpha/5-fluorouracil and their clinical significance. PLOS ONE 8, e56197 (2013). 